IRA-International Journal of Education \& Multidisciplinary Studies

ISSN 2455-2526; Vol.10, Issue 03 (March, 2018)

Pg. no. 48-60.

Institute of Research Advances

http://research-advances.org/index.php/IJEMS

\title{
Challenges Faced by Secondary Teachers in Teaching Arts Education in Fiji - A Case Study of Western Division
}

Mohammed Feroz Ali

Lecturer, School of Education, College of Humanities and Education, Fiji National University, Fiji.

Type of Review: Peer Reviewed.

DOI: http://dx.doi.org/10.21013/jems.v10.n3.p4

\section{How to cite this paper:}

Ali, M.F. (2018). Challenges Faced by Secondary Teachers in Teaching Arts Education in Fiji - A Case Study of Western Division. IRA International Journal of Education and Multidisciplinary Studies (ISSN 2455-2526), 10(3), 48-60.doi: http://dx.doi.org/10.21013/jems.v10.n3.p4

(C) Institute of Research Advances.

\section{(cc) EY-NC}

This work is licensed under a Creative Commons Attribution-Non Commercial 4.0 International License subject to proper citation to the publication source of the work.

Disclaimer: The scholarly papers as reviewed and published by the Institute of Research Advances (IRA) are the views and opinions of their respective authors and are not the views or opinions of the IRA. The IRA disclaims of any harm or loss caused due to the published content to any party.

Institute of Research Advances is an institutional publisher member of Publishers Inter Linking Association Inc. (PILA-CrossRef), USA. The institute is an institutional signatory to the Budapest Open Access Initiative, Hungary advocating the open access of scientific and scholarly knowledge. The Institute is a registered content provider under Open Access Initiative Protocol for Metadata Harvesting (OAI-PMH).

The journal is indexed \& included in WorldCat Discovery Service (USA), CrossRef Metadata Search (USA), WorldCat (USA), OCLC (USA), Open J-Gate (India), EZB (Germany) Scilit (Switzerland), Airiti (China), Bielefeld Academic Search Engine (BASE) of Bielefeld University, Germany, PKP Index of Simon Fraser University, Canada. 


\begin{abstract}
Art and craft education is the area of learning which is based upon the visual, drawing, painting, pottery, weaving, print making, making artifacts using recycled materials and to name a few. This research focuses on the challenges faced by secondary teachers in teaching Arts Education. The idea was researched to establish how art and craft education can be utilized to increase levels of confidence, motivation and skills in Secondary school teachers. The research used a mixed method approach for gathering results. This study, using a questionnaire designed by the investigator, provided an insight into secondary art and craft teachers, principals and curriculum developers of art education. A group of 20 participants was selected through convenient sampling for the purpose of this study. Findings show a positive correlation between the art and craft program at the center of this research and the advancement of the skill acquisition, motivation and confidence. The recommendations after the study and analysis of results should enshrine great details on how art and craft can become a mainstream subject and shed its light on the minds of the children to gain its due respect and position to where it naturally belongs.
\end{abstract}

Key words: Artifacts, motivation, skills, confidence, challenges, Specialist Art and Craft teachers, curriculum, pedagogical skills, inter-discipline, multiculturalism.

\title{
Aim of the Study
}

To find out the challenges faced by art and craft teachers in implementing the art and craft curriculum in the secondary schools and to suggest solutions to the problems.

\section{Research Question}

1. What are the Secondary School Teachers' perceptions about art and craft (taught?) in schools?

2. Extent to which recommended pedagogical skills are implemented.

3. Degree to which teachers promote arts education in schools.

4. Challenges faced by teachers while implementing/teaching art education curriculum.

\section{Introduction /Back Ground}

Art education is the area to be focused for learning which is based upon the visual, tangible arts drawing, painting, sculpture, pottery, weaving, and fabrics. The school curriculum covers aspects of art education which is Art in 2 dimensional Skills and Processes, Appreciation, Arts in Society and Culture. Art and design as a subject on the curriculum, with craft implied rather than explicit within its content is generally taken for granted as an entitlement for children and young people in formal education. The subject art and craft have an important position in developing general cultural education. It prepares pupils for a number of further education, trades and occupations. Aesthetic competence is a source of development on several levels, from personal growth, via influence on one's personal surroundings, to creative innovation in a larger social perspective. This study examines the challenges faced by art and craft teachers in school that provides adequate directive for quality education and art and craft subject, the level of confidence in its delivery, and issues that may emerge to influence University curriculum development.

These assumed images are under considerable threat in many schools and settings, the paints, kilns and cameras are now actively abandoned. What is happening to our subject, the teachers, children, and young people and ultimately to our creativity, culture, well-being and economic success is to be established.

The arts and crafts subject embodies various traditions, from the craftsman's knowledge of materials, techniques and work processes, via the designer's knowledge of developing ideas and solving problem, to the artist's production of creative works of art. The perception of art, design and architecture are along with raising the awareness of our cultural heritage in a global perspective, important aspects of the subject. Art and craft are a natural element of our cultural heritage. Understanding the arts and crafts of the past and the present in one's own culture and that of others may provide the basis for developing our multicultural society.

Knowledge about form, colour and composition is vital for the creation of products that function, and to successfully communicate through visual messages. This knowledge can contribute to personal development, which is a 
requirement for resolute creative idea development, visual communication and production. Such knowledge can improve the opportunity to participate in democratic decision-making processes in a society where more and more information is communicated visually. The subject has as one of its aims, to help to develop entrepreneurship, cooperation with business and industry, institutions and specialists. In interdisciplinary cooperation on design and technology the subject particularly contributes to the practical-aesthetic aspects of design.

Art and Craft subject are an essential component of every secondary school in Fiji. It is one of the core subjects which must be taken in Year 9 and 10. This is one of the important parts of Fiji's Education curriculum which is facing challenges due to the problems faced by teachers in implementation of the arts and crafts curriculum. Keeping the above view in the mind, this research aims to find out the challenges faced by the teachers in implementing the art and craft curriculum in Secondary schools in the Western part of Fiji. The finding of this research will assist the teachers to use different techniques in teaching art $\&$ craft and will assist to improve unit descriptor as well as strengthen the imagination power and build the child creativeness. It is concerned with making critical judgments' based on a sound knowledge of a variety of contexts; judgments' about cultural values, cultural history, aesthetics, quality, craftsmanship and fitness for purpose, and provides an opportunity for engagement in leisure pursuits that can yield lifelong benefits in health, well-being and life satisfaction. It enriches children and young people's experience of school and college life.

The challenges that would potentially be discussed are largely relevant to Art and Craft curriculum, inadequate resources, including staffing, and, most importantly, ignorance of or refusal to acknowledge, the critical importance of original educational thoughts and practice. In order to highlight the detrimental effects of the problems, judged by many to be fundamental to the problems experienced by the Art and Craft teachers in their education system, it is necessary to see the current situation in its historical context, and in particular identity the influence of challenges and concepts on art and craft curriculum.

The significance of the art and craft in everyday life is not something that can be gauged in firmly realistic terms; whilst arts promote inventive ways of learning, encourage creative responding to phenomena and involve young people in imaginative processes that build up their dilemma solving skills, their true significance derives from their role in providing a sense of continuity and cultural inheritance that provides a sense of communal identity. Practices such as the traditional Fijian mat weaving, helps provide order and harmony in societies seeking to reconcile their traditional way of life with the requirements of the modern world.

Within the situation of formal education the subject supports personal, social, moral, spiritual, cultural and inspired development, and enables participants to employ with and discover visual, perceptible and other sensory experiences and how to be familiar with and communicate ideas and meanings. These opportunities enable them to work with traditional and new media, so that they develop confidence, capability, mind's eye and inspiration.

Through these opportunities they learn to be grateful for and value images and artifacts across times and cultures, to understand the contexts in which they were made. Experiences in art, craft and design facilitate them to learn how to reproduce significantly on their own and others' work. They learn to think and act as artists, makers and designers, working creatively and intelligently. They develop a pleasure of engagement in art, craft and design as critical consumers and audiences an understanding of its role in the artistic and educational industries that shape and enrich their lives.

\section{Literature Review}

Art and Craft is not a special commodity for the enjoyment of privileged subjects. Neither is it a luxury to be indulged in only when more pressing matters have been attended to. Art and craft exists everywhere around us the buildings we put up, in our homes, in the trees we plant, the things of daily use, in the streets, and, in fact, in everything the discerning eye can see. (Lee 1970, p. 2)The Industrial Revolution permanently altered the art and craft production process. It also saw the introduction of arts education in trade schools, as design and industrial drawing grew in relevance. Today, arts education is present in Europe and the United States in a complex network of liberal colleges which offer a broader syllabus of the humanities and social sciences, classroom teaching in conventional schools, formal and informal art institutions, vocational and professional art schools and museum workshops. 
It is a misleading notion to think that the Art and Crafts programme in our schools is meant only for those who cannot study. It is meant for all. Besides playing an important part in the practical and economic aspects of our national development, the Art and Crafts programme in our schools also helps the growth of our children's emotional, aesthetic and cultural life. (Chai 1977, p. 2)

Experiencing and learning in crafts and art is an active mental and physical process which involves both cognition and emotion. Emotions in these processes can vary from joy and enthusiasm to anger and frustration. However, the emotions affect student teachers' attitudes and confidence when teaching art and craft. A growing body of studies reveals there is a link between socio-emotional intelligence and academic success, as well as the positive impact of socio-emotional programmes on academic skill development (Ciarrochi et al. 2006). The importance of emotional intelligence extends to understanding ourselves and others, improving individual assessment, and contributing to social and cultural practices. By extension, teachers' emotions towards a subject impact their teaching of it.

In fact, the results of a recent study of teachers' emotions while attending courses in higher education (Postareff \& Lindblom-Ylänne 2011) imply that those teachers with learning-focused profiles expressed the most positively charged emotions towards teaching. Furthermore, those teachers with content-focused profiles proved to have neutral or negative feelings toward their teaching and the development of teaching.

Another study conducted by Miraglia (2006) investigated show prior experiences, perceptions and attitudes of 18 pre-service generalist teachers contributed to their anxiety in making and teaching art. According to Miraglia, contributing factors to anxiety in creating art include a lack of art knowledge, a fear of making mistakes and negative responses from peers or from former teachers or both. The study concluded that increasing pre-service teachers' art knowledge and competence could reduce their fear and anxiety in art making and boost pre-service generalist teachers' confidence. One of our questions enquired whether one short compulsory course in arts and crafts which both Finnish Med. and Maltese BEd. students take in their respective universities is enough to noticeably change student teachers' attitudes. Several educational psychologists have launched frameworks of emotions and learning such as Bloom's taxonomy (Bloom et al. 1956), multiple intelligences (Gardner 1999) and emotional intelligence (Mayer et al. 2000; Bar-On 1997; Goleman 1995), which shed light on how these all impact each other.

According to Bloom et al. (1956), the learning process includes three overlapping domains: cognitive (knowledge), psychomotor (skills) and affective (attitude and growth in feelings or emotional areas). Theories of emotional intelligence consider introspective and self-reflective capacities important to self-awareness and the ability to understand a person's own emotions, goals and motivations. Goleman (1995) even considers emotional competence as one of the abilities that help one to motivate oneself, to persist in the face of frustrations, to feel confident and to be socially competent. Yet, emotion is an aspect that is often neglected in education despite its obvious effect on learning. Other key factors that affect student teachers' professional growth are prior experience, the quality of their own school experience and the content of their initial teacher education (ITE) programme (Kagan 1992; Hudson 2003; Oreck 2004; Russell-Bowie 2012) all of which, in turn impact their confidence to teach the subject.

Generalist primary teachers' levels of confidence in teaching the arts subjects is an area of concern (Green \& Mitchell 1998; Russell-Bowie 2012; Byrne 2005; MacDonald et al. 2006), as confidence to teach a subject can significantly influence teaching outcomes (Bandura 1997). The quality of their own school experiences visibly influences the way student teachers' respond to their ITE programme and their perceptions of teaching (Kagan 1992; Nettle 1998; Lam \& Kember 2004; Russell-Bowie 2012). In fact, personal values and beliefs about teaching actually become more elaborated considerably during pre-service teacher training and can be resistant to any effective change

The reasons for neglecting the Arts dates back to time in Namibian history, when colonialism and in particular the apartheid system divided the country. Cathy McRoberts mentions how the word craft has still repercussions from the time of apartheid as craft was usually offered for native Namibians and higher concept, art for white pupils. Coetzer confirms that visual art was more likely to be offered in the administrative white schools, while craft, music and dance based teaching was offered for the black population. Opinions about to what extent even crafts were materialized during Bantu education, differ. According to the old teaching timetable a subject called: Arts, crafts, gardening, was offered for two and a half hours per week, (Murphy 1978,10) but as the compiling of those three themes suggests; the subject emphasized vocational, functional, simple work done by hand. Cathy McRoberts mentions practical leather and wood work as technical craft examples offered to non-white schools. 
Art and Craft shows a new viewpoint from the world, some spot that we haven't been realized before" notes Helena Sederholm, a Finnish professor and active commentator on contemporary art. She mentions how art is a way of knowing even though different from science. (Sederholm, 2013) Art relies more on empiricism, but like Efland writes in his book "Art and cognition" viewpoints are formed by understanding causal interdisciplinary relations between different themes. Empirical knowledge and art works are representations from the world and should be considered as a valuable source of knowledge. (2002, 76-77)

\section{Significance of the Study}

This research will help to find out the pedagogical needs of the secondary school teachers teaching art and craft in the secondary schools in Fiji. It will help to make adjustments to the art and craft units to train our students at school to face the demands of the subject and the needs of the students. This study will also suggest ways in which we can give more value to the teaching of art and craft in secondary schools, since such knowledge can influence teacher pedagogy in secondary Schools. In accumulation to that, it will help art teacher educators to be better encourage and teach suitable mechanisms and skills to pre- service teachers, making clear their magnitude in art education overall. The results of this study will greatly influence teacher educators' decisions in planning teacher education in art education. This research will throw light on how art education has been perceived and how this perception hinders the learning and development of creative abilities in pre service teachers. This will help the teacher educators to tailor the teaching of the art education courses to develop interest and inventiveness in the pre-service teachers. Finally, the findings will have the potential to influence changes at tertiary levels in the area of art education, especially in the case of Fiji.

\section{Sample}

Research is systematic investigation into and study of materials and sources in order to establish facts and reach new conclusions. Every research needs effort, time and dedication for relevant and appropriate conclusions can be determined. The collection of participants included 20 Secondary School's PEMAC Teachers where there were 12 Male and 8 Female Teachers. The teachers experience ranged from 6-20 years in the Western schools of Fiji .Out of the twenty PEMAC teachers 10 teachers had Physical Education / Music and the other 10 had Physical Education /Art and Craft as the Majors. There were 10 school Principals who were interviewed and the interview of the Senior Education Officer, Curriculum Advisory Services was also done. This method of sampling made it easier for the researcher to collect the data as the researchers was from the western part of Fiji.

\section{Methodology}

For the purpose of this study, quantitative and qualitative research was combined thus it was a mixed method of study. In mixed method approach, both qualitative and quantitative data collection techniques, methods and procedures were utilized.

According to Creswell and Clark (cited in Creswell (2014) there are four basic types of mixed method design commonly used in educational research. Each of these methods has different characteristics, which is discussed as follows:

1. The Convergent Parallel design - researcher, gives equal priority to both qualitative and quantitative data, analyses both datasets separately, compares the results from the analysis of both data sets and makes an interpretation as to whether the results support and contradict each other;

2. The Explanatory Sequential Design - the researcher places a priority on quantitative data collection and analysis and then collecting qualitative data to help explain or elaborate on the quantitative results;

3. The Exploratory Sequential Design- the researcher first gathers qualitative data to explore a phenomenon and then collecting quantitative data to explain relationship found in qualitative data;

4. The Embedded Design- the investigator collects qualitative and quantitative data simultaneously and sequentially, but to have one form of data play a supportive role in the other form of data (Creswell, 2014).

Qualitative Data Collection Techniques Data collection methods employed in this research was interviews: semistructured in-depth interview, observation, and document analysis. Interviews were one of the main tools used for 
data collection in the study. Interviews are typically classified as being structured, semi-structured, or open-ended (Mertler, 2012). In this, study the researcher used semi-structured interview.

\section{Semi-Structured in-Depth Interview}

Semi-structured in-depth interviews explored the understanding of the art and craft in secondary schools in the western division in Fiji. According to Denzin and Lincoln (2003), interviews create valuable data about lived experience and its meanings. They added that in interviews the researcher obtains comprehensive and in-depth experiential description of a situation. It is one of the reasons for the selection of this method as it can gather reliable data based on participant's authentic encounters. The in-depth interview method has numerous advantages to collect data in research. Sarantakos (2005) and Angrosino and Perez (2003) argued that interview method has a huge advantage and valuable where it will give an occasion for the researcher to examine the insights and opinions of members as well as to observe nonverbal expressions of participants through investigation.

\section{Qualitative Data Analysis}

According to Mertler (2012) analysis, qualitative data is an inductive method, comprising the compression of information collected by organizing it into significant themes and patterns. The art and craft education teachers were given questions. A coding scheme was developed where the researcher groupedthe data with similar information. In addition, data was analyzed and organized into themes to portray the case (Mesake, 2013). Therefore, the data should be examined thoroughly. The main feature of each category is described, and in the final step, the researcher will interpret the data that has been coded. Data was collected through interview, observations, and documents from teachers and the principals of the sampled schools.

\section{Quantitative Data Collection}

Quantitative data are numerical in simple terms anything that can be quantified; it can also include ratings of one's feelings, attitudes, interest or perception on some numerical scale (Metler, 2012, p. 132). It includes surveys questionnaires, rating scales, and checklist. The quantitative data collection techniques were used in the research survey questionnaire, which had a demographic information sheet, and questionnaire with Likert-type rating scales. Questionnaires provide researchers with written information produced by participants. Questions were specific for collection of information with some open-end questions for the participants to respond freely (Mesake, 2013). Both the open-ended and closed questions were used; Questionnaires was filled by PEMAC teachers.

\section{Instrumentation}

The survey questionnaire was developed with relevant literature review . The survey consists of demographic information, closed and open questions and a Likert scale. The administration of the survey questionnaire addressed all research questions.

Analysis of quantitative data was done using deductive method, using descriptive or inferential statistics. Descriptive statistics are moderately manageable mathematical methods used to simplify, summarize and organize large amounts of numerical data. It can be visually described with frequency distribution tables such as graphs, histograms, bar charts and pie charts (Mertler, 2012). Descriptive statistics are used to illustrate the fundamental features of the data in a study. They provide simple summaries about the sample and the measures. Together with simple graphics analysis, they form the basis of virtually every quantitative analysis of data (Trochin, 2006). SPSS was used for cross tabulation and basic descriptive studies for this study.

\section{Findings}

Research comprises "creative and systematic work undertaken to increase the stock of knowledge, including knowledge of humans, culture and society, and the use of this stock of knowledge to devise new applications. The findings of this study discovered that the teachers went through numerous challenges when implementing the art and 
craft curriculum and are concerned with the teaching expectations of the Curriculum Advisory Services and the other stake holders'. A number of factors contributed to them believing they could not fulfill all of these teaching expectations. Some of the key issues teachers frequently referred to in their interviews were:

- The discernment of the art and craft teachers and the administrators

- The pedagogical skills teachers possess for implementing the curriculum

- Teachers' evaluation of their own creative art knowledge and skills; the level of confidence expressed by individual teachers to teach arts

- Challenges in the system which hinder the implementation

Fig. 1

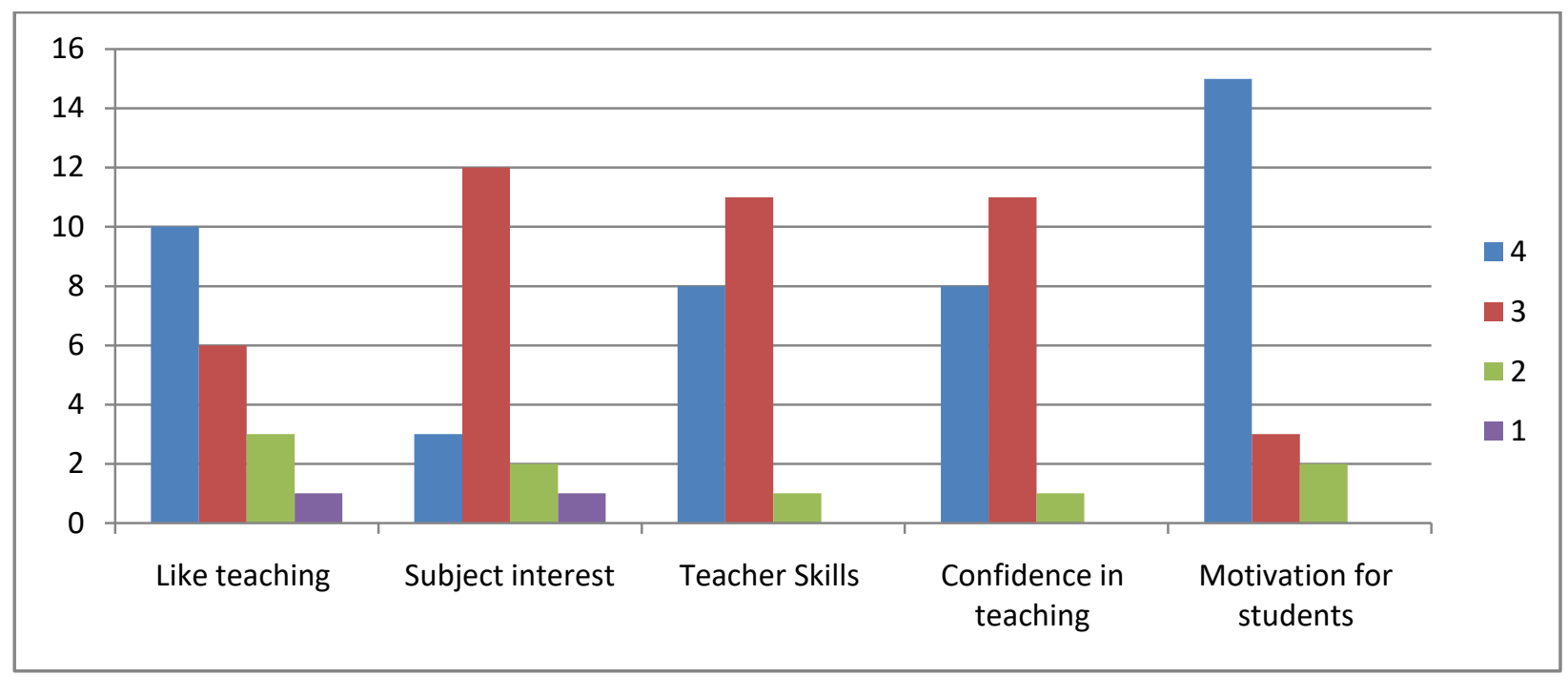

Majority of the participants indicated that the arts have value in learning and in the Fijian society. The teachers not only focused on their own values associated with art and craft, but also on their perception of the values and attitudes held by society in general, students, and community in Fiji Teachers described how they valued the art and craft for the foundational skills they provided for learning and development. They related how they used the creative arts to:

- Develop fine motor skills

- Assist in the development of social skills

- Develop student confidence

- Developed creative thinking

Despite enlightening that they valued arts for the way they assisted in the promotion of these outcomes, it was noted that there was petite attention given to cognitive aspects of learning in the arts. Many of the teachers and the principals related that art and craft 'not as academic' as other curriculum areas. Numerous also admitted that art and craft was practiced irregularly, and that they gave priority in the areas in which students had examination. The likeness of the subject precisely developed the confidence in the teachers and their class was more of effective and result oriented.

Subjects of this research often stated that they had particular interest in one area or another of Art and Craft, although they had some difficulty in describing if it was interest originated, or it was an external factor.

According to the teachers who were interviewed they classed, their families were influential in both positive and negative ways in developing interests and skills. Despite their view that the creative arts did not have educational status in the school and community, many of the teachers emphasized that they believed attitudes and opinions were shifting. They indicated that the creative arts were continuing to grow in importance within education and in other aspects of life. 
The subjects who responded to the questions had highlighted and this was inferred through analysis of results that those who were not qualified in the subject lacked the necessary skills to accomplish the objectives of the lesson. This had become a means of struggle and ultimately the teachers lost interest in the subject. As a result, the subject content was delivered as a task just to fulfill the requirements; however, no sustainability was achieved. When the teachers lacked interest in the subject, they failed to motivate themselves as well as the students to inculcate the skills or art and craft into their daily lives.

Fig. 2

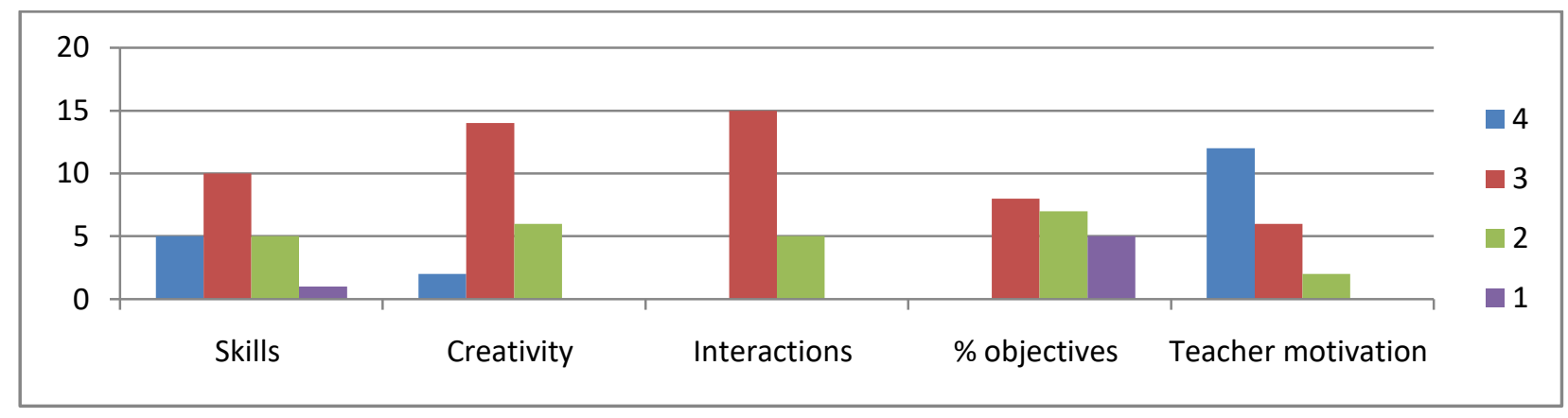

All of the participants stated that they utilized the skills of other people to assist learning in different aspects of the art and craft. These people were often referred to as 'consultants', 'artists', 'colleagues', 'specialists', 'the parent body' and 'highly qualified or trained people'. This added the dimension of creativity and interactions.

The delegation of teaching ranged from total delegation to partial delegation, and included working together in a partnership with others. At least half the participants said they delegated the responsibility for teaching art and craft to other people for maximum objectives to be achieved.

The rationale for this delegation was that they felt very uncomfortable teaching in this specific subject area. Many participants expressed the view that their arts experiences in the school education environment had been limited and this was restricted. These restrictions in turn have become a factor that affected the motivation of teachers as well as students. The data analysis revealed varying levels of teacher motivation in relation to teaching in the arts disciplines. The words and phrases teachers used to describe their degree of motivation were used to group them into one of four levels, expressed as: highly motivated, fairly motivated, poorly and rarely motivated.

A motivated teacher is crucial to a successful classroom. They will look at teaching through a different lens, and, in doing so; motivate their students in their learning too. Motivation helps to energize, direct and sustain positive behavior over a long period of time. It involves working towards goals and tailoring activities to achieving this purpose. It also helps to drive creativity and curiosity, sparking the desire needed for students to want to learn more. It isn't just a case of getting pupils interested in learning in the moment, but also in growing the underlying goals and aspirations pushing their entire academic studies. It is about motivating them beyond the initial task or feeling of accomplishment and appreciating how 'deferred gratification' plays into the role of education in order for them to work towards a greater, larger objective. (Thomas L. 2016) This is known as 'intrinsic motivation' and research has found it to be of key importance. 
Fig. 3

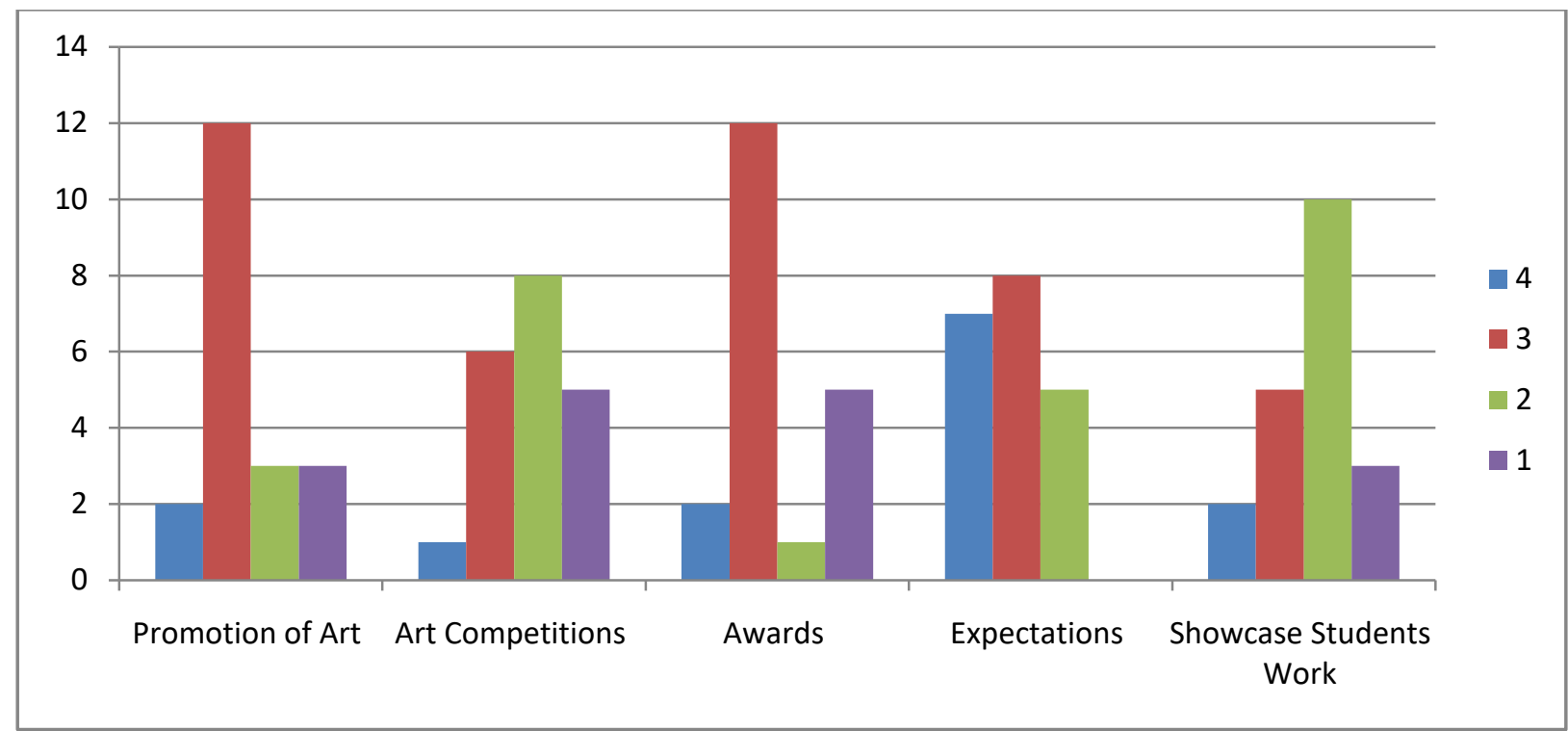

Collectively, the participants indicated that the art and craft have value in learning and society and in promotion of the subject the teachers not only focused on their own values associated with the Key Learning Area, but also on their perception of the values and attitudes held by society in general, students, and students' family members. Participants described how they valued the art and craft for the foundational skills they provided for learning and development. They related how they used the creative arts to:

- Develop fine motor skills

- Assist in the development of social skills through art competitions and awards

- Develop student confidence through competitions and awards

- Enrich learning throughout the curriculum as cross-curricular programming.

Despite revealing that they valued the art and craft for the way they assisted in the promotion of these outcomes, it was noted that there was little attention given to cognitive aspects of learning in art and craft. Many of the teachers related how the expectations of art and craft were 'not as academic' as other curriculum areas. Many also admitted that art and craft subjects were practiced irregularly, and students work was hardly showcased and that the priority they give to the collective area was often lower than other areas within the school's curriculum. Participants often stated that they had particular interest in one area or another of the areas, although they had some difficulty in describing where their interest originated. 
Fig. 4

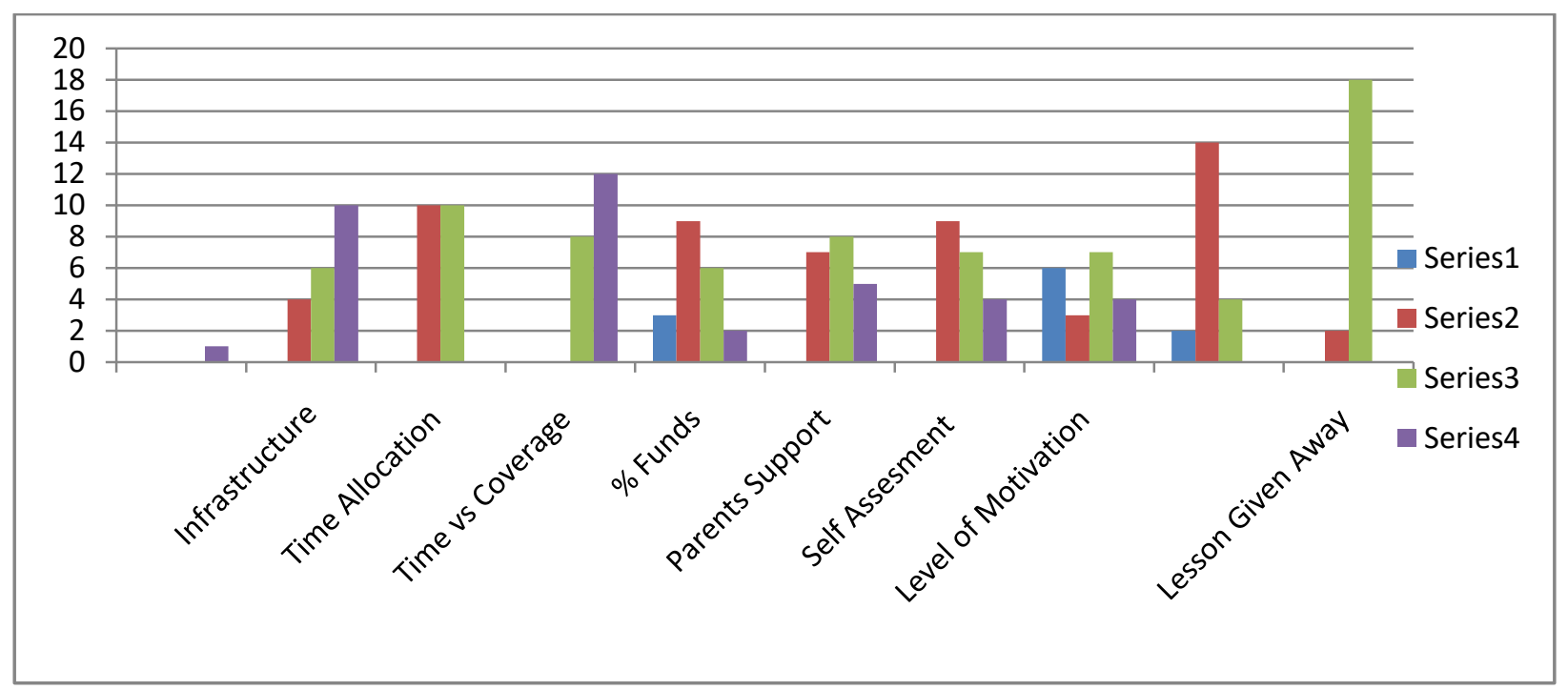

A number of factors contributed to the fact that the expectations of the aspirations of the subject were not being met. Some of the key issues teachers frequently referred to in their interviews were the availability of infrastructure that is a proper art and craft classroom with appropriate furniture, printing tables, isle for painting and display boards for students work. These are some of the equipment that constitutes an Art Room.

The issue of time and quantity of subject matter in learning and development was a concern of all the participants. Many participants used the terms like 'over-crowded' or 'crowded' when describing the state of the curriculum. The teachers expressed feelings of being overwhelmed with the needs of all of the curriculum areas, and said this resulted in a reduction in the time they devoted to art and craft education. Some teachers felt that the time devoted to the art and craft was also pressured by the preparation necessary to facilitate activities - such as provision of art materials, preparation and clean-up, as well as finding resources. Additionally, the majority of teachers believed their teaching time was dominated by an attention to other examinable subjects because the demands of departmental directives necessitated that students achieve benchmark standards in literacy and numeracy.

The Ministry of Education has allocated special percentage of its grant to the PEMAC department, however it is not specifically for art and craft, the money allocated is mostly used for Physical Education and Competitive sports which the school takes part in and hence art and craft is neglected where only human resources are devoted towards it. This is one of the prime reasons for the neglect of the subject.

Since parents already have a preconceived idea that the future of their children lies in the percentage marks their children would achieve in the academic subject, so that requires greater attention, hence if a child is seen to be devoting time for art and craft, the parents discourage them and request for their focus to be in examinable subjects only. There is hardly any appreciation for a creative art work done by students, subsequently, the priority of a child changes to areas where they are acknowledged and accolade. Unfortunately, there is no recognition by the Ministry of Education with any documentary evidence for the hard work and effort of the art and craft teachers and students. In the current systems of appraisal in school for teachers is the exam results, however, it is only left to wonder for the art and craft teachers as to how their performance will be measured for promotion and monetary appraisals, thus this is a means of discouragement and this lacks motivation for both teachers and students. 
Fig. 5

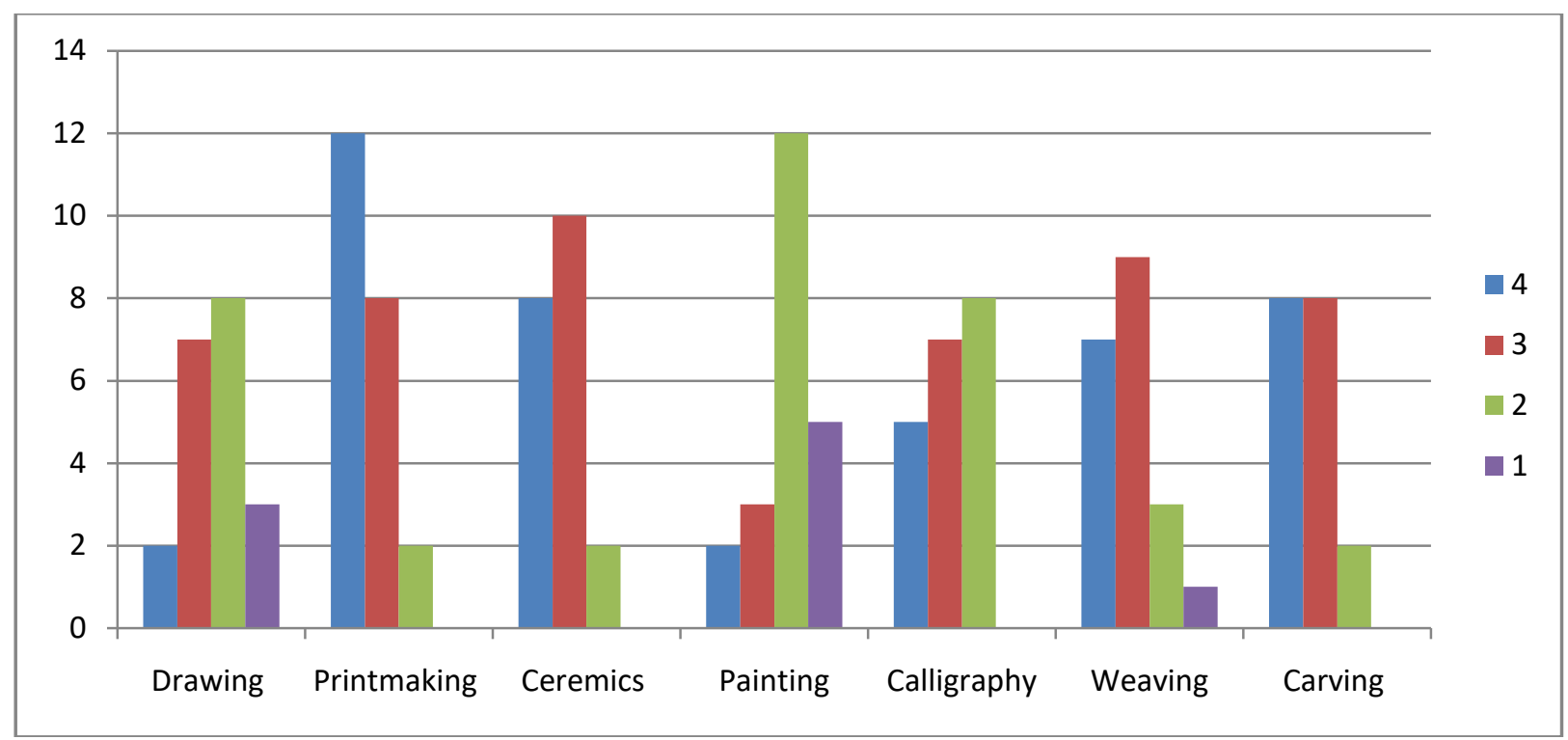

The reality in the Fijian school system is that not all art and craft teachers are qualified to teach art and craft, however, since in schools there is only a few places for Physical Education, music and Art and Craft teachers, therefore, some PE and Music graduates are made to carry out the obligations as a art and craft teacher. This is a disadvantage for them as they lack the pedagogical skills of teaching the art and craft subject.

Drawing, which is a basic element of art and craft is a graphic representation by lines of an object or idea, as with a pencil; a delineation of form without reference to color.

Overall, the participants considered that their individual skills and knowledge in each of the art and craft based skills influenced their ability to adequately deliver effective practices. In the following statement, the subjects raised a point about the quality of art and craft teaching being highly variable among teachers: It was found that most participants had similar understandings. It was also noted that each of the teachers tended to avoid speaking about areas within art and craft where they believed they did not have adequate skills and knowledge.

The data analysis revealed varying levels of teacher confidence in relation to teaching in the art and craft disciplines. The words and phrases teachers used to describe their degree of confidence in each of the different aspects were alarming which ranges from very low skills to mediocre skills. These are presented in Figure 5, where the levels of confidence for each subject area are compared. The figure shows how the participants felt in teaching art and craft in the classroom and what level of skills they had in the seven different variables of the subject.

\section{Recommendation}

A number of recommendations for future directions in educational policy and practice stem from the study. These include a significant increase in the amount of teacher training. Tertiary institutes can provide short courses in order to provide us skilling of the existing teachers in the subject. This could be facilitated by the ministry of Education by liaising with tertiary institutions. Once the existing teachers are skilled, naturally their interest to utilize their knowledge will be boosted and thus motivation levels will automatically rise to substantial levels.

The appointment of more art and craft specialist in schools will take the subject to another level so that these specialist take the subject at various levels and at the same time art and craft could be considered to be a subject up to Year 13 which is given due recognition as it should become a core subject and after becoming examinable, results are listed on the academic transcripts, hence the subject will be given priority. 
For the moment one forty minute class is too less for the students to showcase their real skills and talents which they can practice after being taught. An equal allocation of time to Art and craft as other subjects should be allotted for the subject to bloom to its natural strength. Additionally, schools provide workshop for industrial arts subjects, a structured garden for agriculture; however, there is no specialist room for art and craft. This area needs to be looked at for the betterment of the child who possess untapped skills and talents in art and craft which shall provide them with opportunities to so like the Technical colleges provide space for other courses like cooking, engineering, carpentry and so on.

Once the above recommendations are addressed, the skills, knowledge, motivation and confidence of teachers as well as students will all fall in its right place. Since the interested students will be engaged in what they like to do best, issues like graffiti, and other issues of the school will be solved by itself, as students will have things to be done on their plates where their interest lies.

\section{Conclusion}

A number of valuable outcomes emerged from this study. Importantly, the study helped to establish a better understanding of the values and attitudes influencing approaches to art and craft education in the secondary school system. The findings raise some of the core and contentious issues in regard to art and craft education in Fiji, focusing on the central question of whether it is realistic to expect secondary school teachers to teach effectively in all areas of the art and craft curriculum.

In this respect the study supports Alexander et al. (1992) in the proposition that the secondary education systems art and craft curriculum is a far too demanding expectation of a generalist teacher's subject knowledge. Under such an arrangement it appears that art and craft teachers suffer the most in their daily deliberations. Specifically, the breadth of knowledge and experience needed in order to teach all the art and craft subjects' components well was viewed by many of the participants in this study as beyond the skills of most Physical Education teachers.

Furthermore, many of the participant teachers implied that because departmental directives in more recent years have demanded more time be spent on literacy and numeracy, this had direct consequences for the art and craft Key Learning Areas. They also admitted it was difficult to have consistency and regularity in the art and craft curriculum, because of the time constraints and the lower educational priority given to the subject area in the curriculum. There are, however, promising signs that in future teachers will receive greater support at a systemic level. This arises because the government particularly Ministry of Education must understand the potential of art and craft in fostering a culture of creativity and innovation in Fiji's school systems.

\section{References}

[1] Angrosino, M.V. \& Mays de Perez, K.A. (2003). Rethinking observation: From method to context. In N. Denzin \& Y. Lincoln (Eds.), Collecting and interpreting qualitative materials (2nd ed., pp. 107-154). Thousand Oaks: Sage

[2] Chai Chong Yii. "Speech by Mr Chai Chong Yii, Senior Minister of State for Education at the Official Opening of the Singapore Youth Art Centre at Hotel Premier, 7 May at 1730hrs”. Singapore: National Archives, 1977.

[3] Creswell, J. W. (2014). Educational Research: Planning, Conducting, and Evaluating Quantitative and Qualitative Research (4TH ed.). Edinburgh Gate, Harlow, England: Pearson Education Limited.

[4] Denzin,N.,\&Lincoln,Y.(2003) Collecting and interpreting qualitative material, USA: Sage publication.

[5] Green, L., \& Mitchell, R. (1998) The effectiveness of initial teacher training partnership in preparing students to teach art in primary school, British Educational Research Journal, Vol. 24, No. 1, pp. 95-105

[6] Goleman, D. (1995) Emotional Intelligence. New York: Bantam Books

[7] Kagan, D. M. (1992) Professional growth among pre -service and beginning teachers, Review of Educational Research, Vol. 62, No. 2, pp. 129-69

[8] McDiarmid, G. W. (1991) What teachers need to know about cultural diversity: restoring subject matter to the picture, In M. M. Kennedy [Ed.] Teaching Academic Subjects to Diverse Learners. New York: Teachers College Press, pp. 257-70

[9] Mayer, J. D. (2006) A new field guide to emotional intelligence. In J. Ciarrochi, J. P. Forgas \& J. D. Mayer [Eds] Emotional Intelligence in Everyday Life, 2nd edn. New York: Psychology Press, pp. 3-26

[10] Minichiello, V., Aroni, R., \& Hays, T. (2008). In-depth interviewing (3rd edn.). Melbourne: Longman/Pearson Australia

[11] Miraglia, J. L. (2006) Conceptions of art: a case study of elementary teachers, a principal and an art teacher. Doctoral dissertation, University of Massachusetts, Amherts. Dissertations Abstracts International, 138 (UMI No. 3242105 
[12] Lee Chiaw Meng. "Speech by Dr Lee Chiaw Meng, Parliamentary Secretary, Ministry of Education, at the Singapore Youth Festival 1970 Art and Craft Exhibition at 5.30pm, Thursday 23 July at the Victoria Memorial Hall”. Singapore: National Archives, 1970.

[13] Sarantakos, S. (2005). Social Research. (3rd Ed.). Melbourne: Macmillan Education.

[14] Postareff, L. \& Lindblom-Ylänne, S. (2011) Emotions and confidence in teaching in higher education, Studies in Higher Education, Vol. 36, No. 7, pp. 799-813

[15] Robinson, K. (2001). Out of our minds: Learning to be creative. West Sussex: Capstone Publishing.

[16] Trochin, W., M. K. (2006). Qualitative Validity. Retrieved September 26, 2016 from Research Methods Knowledge Base website: https://www .socialresearchmethods.net/kb/ qualval.php. 